\title{
Steel Structure of a Tunnel Dormitory for the Armed Forces Troops
}

\author{
Taher El-Bitar ${ }^{1 *}$ and Ahmed Shehata ${ }^{2}$ \\ ${ }^{1}$ Professor at Central Metallurgical R\&D Institute (CMRDI), Egypt \\ ${ }^{2}$ Civil \& Structural Engineer, Research grant student, Egypt
}

*Corresponding author: Taher El-Bitar, Professor at Central Metallurgical R\&D

Institute (CMRDI), Egypt.

\begin{abstract}
The current steel structure is used mainly as a dormitory for the armed forces troops, who are facing terrorist aggression. It is supposed that the structure of the dormitory can withstand 70 tons as a live load. Easy installation and dismantling for transportation are considered as essential requirements. The steel structure is processed of grade X42, with $8 \mathrm{~mm}$ thickness, according to the American Petroleum Institute specifications (API5L). The steel has a chemical composition comply with grade X42, as it contains (max.) $0.28 \mathrm{wt} \% \mathrm{C}, 1.30 \mathrm{wt} \% \mathrm{Mn}, 0.030 \mathrm{wt} \% \mathrm{P}$, and $0,030 \mathrm{wt} \% \mathrm{~S}$. On the other hand, the steel sheets would possess mechanical properties as; 290 -496 MPa Yield stress, 414 -758 MPa Ultimate tensile strength, and $22 \%$ Elongation. The modulus of elasticity is considered as $20000 \mathrm{MPa}$. The main body of the dormitory steel structure consists of segments. Each segment consists of two halves of $200 \mathrm{~cm}$ diameter pipe with $8 \mathrm{~mm}$ wall thickness and $150 \mathrm{~cm}$ pipe length. The main body of the dormitory contains 2-3 segments. An additional subsidiary unit is usually constructed as a main entrance with vertical sides and arch roof. A Finite Element Analysis (FEA) was used through SAP 2000 software package as a tool for quick and precise physical simulation to apply the live and died loads and detecting any deflections, permanent deformations and moments about the X- and Y-directions in the steel structure of the tunnel dormitory. It is found that $8 \mathrm{~mm}$ wall thickness is the optimum, where the dormitory steel structure shows $2.72 \mathrm{~mm}$ maximum deflection under loading conditions, which represents 0.13 deformation\% in the Z-direction. The moments are very low, as they reach to 0.023 and 0.066 t.m about the X-and Y-directions respectively.
\end{abstract}

\section{Introduction}

Fighting against terrorism is not a conventional battle. Conventional wars are controlled with well-known rules. On the other side, terrorism is deciding his own rules. Consequently, the troops should be ready for any unexpected movements of terrorists. At the same time, commanders are worry about the troops during the rest and/or battle periods. Secured troops dormitory is an essential element in the fighting system. The current work, is dealing with design of a tunnel dormitory steel structure for the armed forces troops. It is supposed that the steel structure of dormitory can with stand 70 tons as a live load. Easy installation, dismantling, and transportation are considered as essential requirements. The dormitory needs for previous preparations before installation as.
1. The main entrance door should be directed towards north-west direction for better natural ventilation.

2. A ground groove should be prepared with the following dimensions: $250 \mathrm{~cm}$ width, $250 \mathrm{~cm}$ depth, and $500-650 \mathrm{~cm}$ length (for 2-3 dormitory segments), in addition to $250 \mathrm{~cm}$ ramp.

3. The steel structure is processed of grade $\mathrm{X} 42$, with $8 \mathrm{~mm}$ thickness, according to the American Petroleum Institute specifications (API-5L) [1]. The main body of the dormitory can contain 2-3 segments. Each segment consists of two halves of $200 \mathrm{~cm}$ diameter pipe with $8 \mathrm{~mm}$ wall thickness and $150 \mathrm{~cm}$ 
length. Fig. 1 shows a half of $200 \mathrm{~cm}$ diameter pipe with $8 \mathrm{~mm}$ wall thickness and $150 \mathrm{~cm}$ pipe length, while Fig. 2 represents a complete segment of the dormitory body. The dormitory is provided with a main entrance having vertical sides and arch roof as presented in Fig. 3, while Fig. 4 sketches a combination between the main entrance and a segment of the dormitory body (Figure 1 and 4).

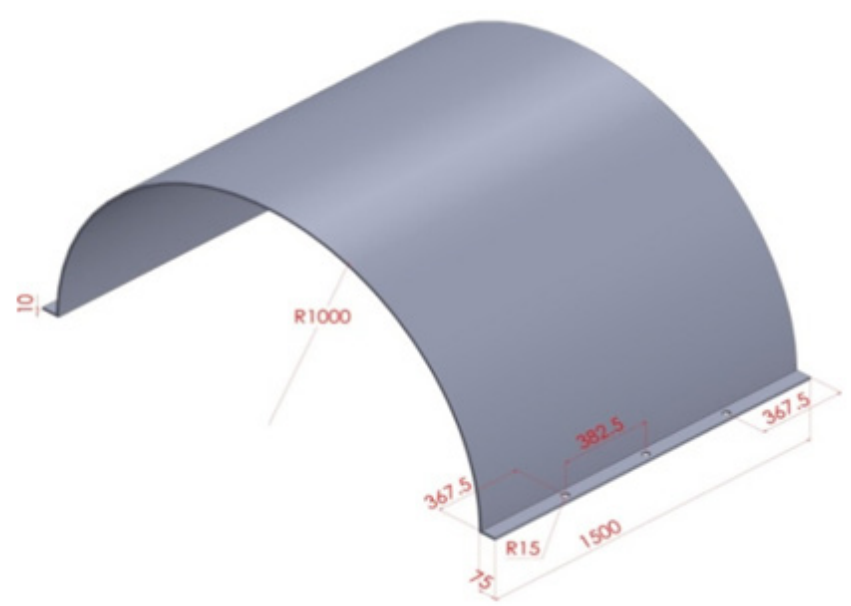

Figure 1: A half of $200 \mathrm{~cm}$ diameter pipe with $8 \mathrm{~mm}$ wall thickness and $150 \mathrm{~cm}$ pipe length.

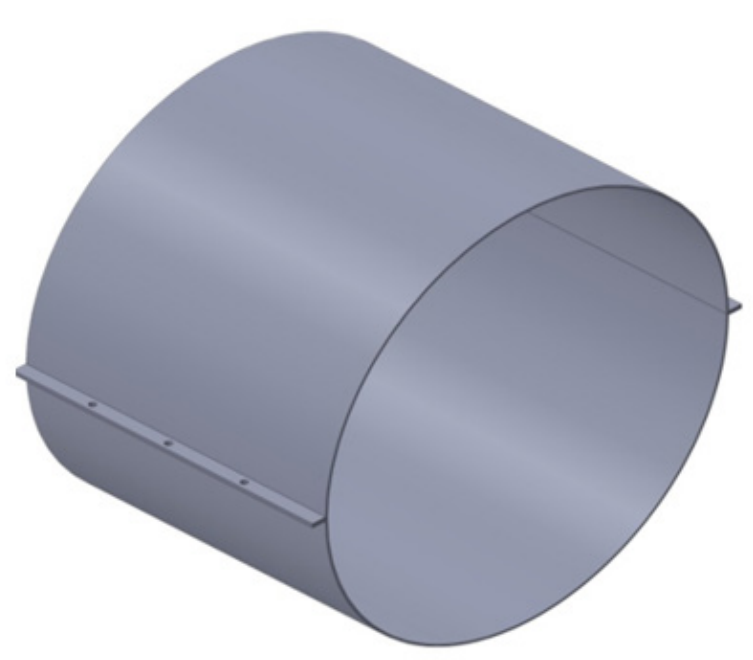

Figure 2: A complete segment of the dormitory body.

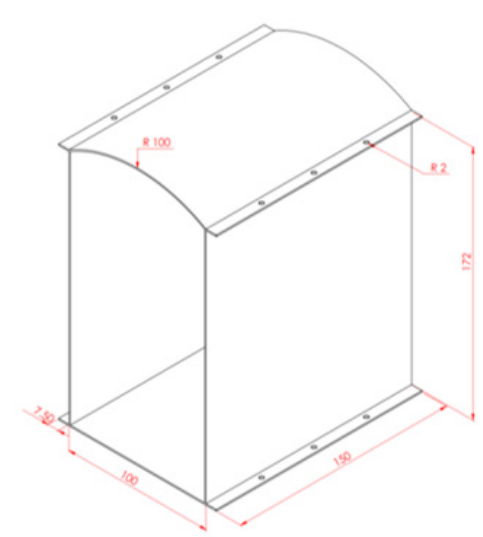

Figure 3: Main entrance of the dormitory. 


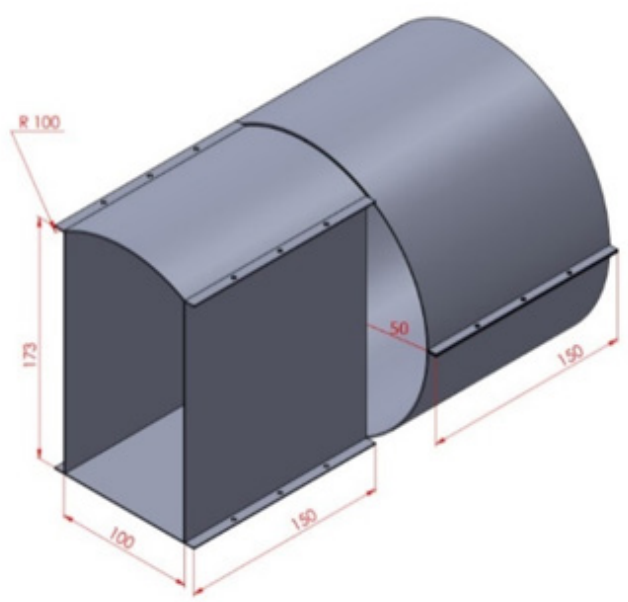

Figure 4: A combination between the main entrance and a segment of the dormitory body.

\section{Structure Analysis}

The steel structure analysis is done using the integrated software SAP2000 [2] as a finite element software package. It was decided that, the pipe section is modeled as a shell thin section which have bending stiffness therefore it resists a portion of the load through flexural deformation [2]. The Pipe section is loaded with its own weight, soil weight above the upper half of pipe and live load of 70 ton. Total working loads is considered as 75 ton distributed on 2-segments projected area. Upper half of pipe has only vertical degree of freedom while lower half is resting on soil so it has no degree of freedom. The modulus of elasticity is taken as
$20000 \mathrm{MPa}$ for the steel grade X42, as stated in a research gate [3]. Simulation trials were carried out for different pipe wall thickness. Fig. 5 represents a relationship between the maximum deflection (due to the working loads) and the pipe wall thickness. After the extensive investigation, a pipe wall thickness of $8 \mathrm{~mm}$ is chosen as the optimum, where the steel structure shows $0.27 \mathrm{~mm}$ as a maximum deflection under loading conditions. Fig. 6 presents the deflection contours of a dormitory consists of 2-segmants under working loads in millimeters. Furthermore, the moments score very low values, as they reach to 0.013 and 0.33 t.m about the Xand Y-directions respectively (Figure 6, 5).

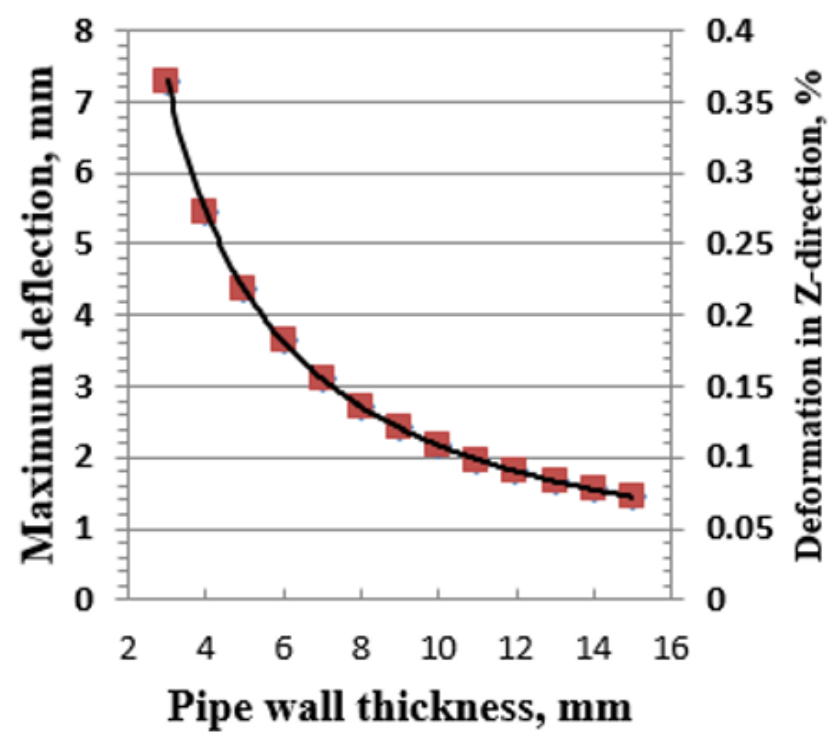

Figure 5: Relationship between the maximum deflection (due to the working loads) and the pipe wall thickness. 

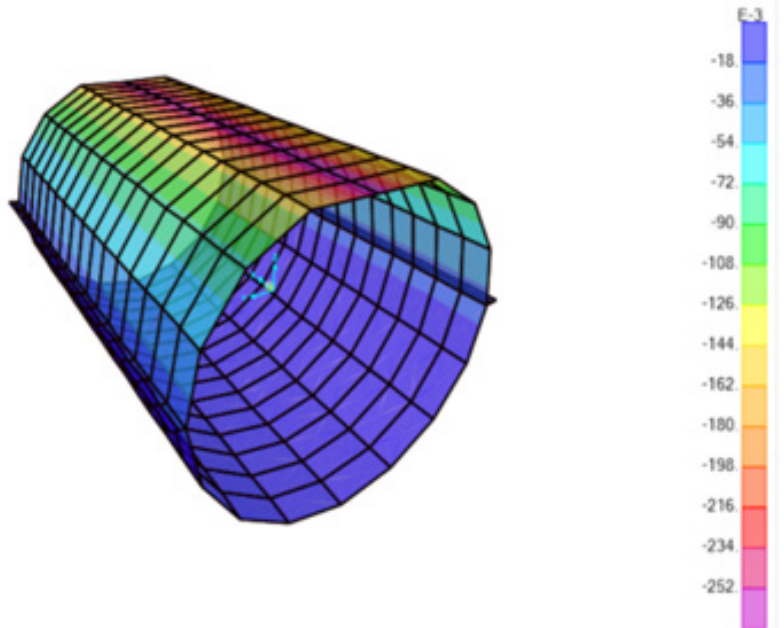

Figure 6: Deflection contours of a dormitory consists of 2-segmants under working loads in millimeters.

\section{Conclusion}

1. A dormitory steel structure for armed forces troops has been successfully designed.

2. $8 \mathrm{~mm}$ pipe wall thickness would be used as the optimum for processing the dormitory body.

3. Physical simulation by Finite Element Analysis shows that the maximum deflection under loading conditions would be $2.72 \mathrm{~mm}$ ( 0.13 deformation $\%$ in the Z-direction ). The moments score 0.023 and 0.066 t.m about the $\mathrm{X}$ - and Y-directions respectively

\section{Acknowledgment}

None.

\section{Conflict of Interest}

No conflict of interest.

\section{References}

1. American Petroleum Institute (API) (2000) specifications 5L for line pipe. $42^{\text {nd }}$ Edition January.

2. SAP (2000) Integrated software for structural Analysis and design. Computers and Structure Inc California 1646N California Blvd Suit 6000 CA 94596 USA.

3. Ameh ES (2017) Eigen value Buckling Computation and Impact on Pipeline Wall Thickness and Subsea Depth. 